\title{
Anode and Cathode Flow Field Design and Optimization of Parametric Performance of PEMFC
}

\author{
Duc Tran Duy ${ }^{1}$, Vinh Nguyen Duy ${ }^{1 *}$, Thuy Cao Thi ${ }^{1}$, Nang Xuan Ho ${ }^{1}$, Hoa Binh Pham ${ }^{2}$ \\ ${ }^{1}$ Faculty of Vehicle and Energy Engineering, Phenikaa University, To Huu Street, Yen Nghia Ward, \\ Ha Dong District, Hanoi, Vietnam \\ ${ }^{2}$ Faculty of Automobile, Hanoi University of Industry, Hanoi, Vietnam \\ *E-mail: vinh.nguyenduy@phenikaa-uni.edu.vn
}

Received: 30 May 2021 / Accepted: 29 July 2021 / Published: 10 September 2021

\begin{abstract}
Regarding pressure loss, water discharge, cell voltage enhancement, and uniform current density, the flow field design for the evenly balanced reacting gas distribution has positively impacted scientists from across the globe looking to enhance PEM performances fuel cells (PEMFCs). A flexible flow field for the anode and cathode is described in this study. In the under-rib design, gas mass transfer is increased, reducing flooding of the cathode and providing for better use of the electrocatalysts. Four different combinations of the flow field, including the multi serpentines, single parallel, interdigitated, and pin flow field configuration, are examined to determine the operating characteristics. These results show that when the active area and operating conditions are identical, the combination of parallel and interdigitated field patterns leads better performance than the other configurations due to its positive effect for supporting water accumulation, water removal, and electrochemical reaction. Furthermore, the parallel flow field patterns show the worst mass transfer characteristics because of the flooding and drying of the membrane caused by uneven flow circulation.
\end{abstract}

Keywords: Polymer electrolyte fuel cell, Serpentine flow field, Under-rib convection, Flow field configuration, Polarisation performance.

\section{$\underline{\text { FULL TEXT }}$}

(C) 2021 The Authors. Published by ESG (www.electrochemsci.org). This article is an open access article distributed under the terms and conditions of the Creative Commons Attribution license (http://creativecommons.org/licenses/by/4.0/). 